\title{
A Noninvasive Method for Quantifying Cerebral Metabolic Rate of Oxygen by Hybrid PET/MRI: Validation in a Porcine Model
}

Lucas Narciso ${ }^{1,2}$, Tracy Ssali ${ }^{1,2}$, Linshan Liu ${ }^{1}$, Heather Biernaski ${ }^{1}$, John Butler ${ }^{1}$, Laura Morrison ${ }^{1}$, Jennifer Hadway ${ }^{1}$, Jeffrey Corsaut ${ }^{1}$, Justin W. Hickss ${ }^{1,2}$, Michael C. Langham ${ }^{3}$, Felix W. Wehrli ${ }^{3}$, Hidehiro Iida ${ }^{4,5}$, Keith St Lawrence ${ }^{1,2}$

${ }^{1}$ Lawson Health Research Institute, London, Ontario, Canada

${ }^{2}$ Department of Medical Biophysics, Western University, London, Ontario, Canada

${ }^{3}$ Department of Radiology, University of Pennsylvania Perelman School of Medicine, Philadelphia, USA

${ }^{4}$ University of Turku and Turku PET Centre, Turku, Finland

${ }^{5}$ National Cerebral and Cardiovascular Center, Suita, Osaka, Japan

Contact: Lucas Narciso or Keith St Lawrence, Lawson Health Research Institute, 268 Grosvenor St., London, Ontario, N6A 4V2, Canada. E-mail: 1narciso@uwo.ca/kstlaw@lawsonimaging.ca

Phone: +1-519-646-6100 x64836/x65737

Fax: +1-519-432-7367 


\begin{abstract}
The gold standard for imaging the cerebral metabolic rate of oxygen $\left(\mathrm{CMRO}_{2}\right)$ is positron emission tomography (PET); however, it is an invasive and complex procedure that also requires correction for recirculating ${ }^{15} \mathrm{O}-\mathrm{H}_{2} \mathrm{O}$ and the blood-borne activity. We propose a noninvasive reference-based hybrid PET/magnetic resonance imaging (MRI) method that uses functional MRI techniques to calibrate ${ }^{15} \mathrm{O}-\mathrm{O}_{2}$-PET data. Here, PET/MR imaging of oxidative metabolism (PMROx) was validated in an animal model by comparison to PET-alone measurements. Additionally, we investigated if the MRI-perfusion technique arterial spin labelling (ASL) could be used to further simplify PMROx by replacing ${ }^{15} \mathrm{O}-\mathrm{H}_{2} \mathrm{O}-\mathrm{PET}$, and if the PMROx was sensitive to anestheticsinduced changes in metabolism.
\end{abstract}

Methods: ${ }^{15} \mathrm{O}-\mathrm{H}_{2} \mathrm{O}$ and ${ }^{15} \mathrm{O}-\mathrm{O}_{2}$ PET data were acquired in a hybrid PET/MR scanner (3 T Siemens Biograph mMR), together with simultaneous functional MRI (OxFlow and ASL), from juvenile pigs $(n=9)$. Animals were anesthetized with $3 \%$ isoflurane and $6 \mathrm{~mL} / \mathrm{kg} / \mathrm{h}$ propofol for the validation experiments and arterial sampling was performed for PET-alone measurements. PMROx estimates were obtained using whole-brain (WB) $\mathrm{CMRO}_{2}$ from OxFlow and local cerebral blood flow (CBF) from either noninvasive ${ }^{15} \mathrm{O}_{-} \mathrm{H}_{2} \mathrm{O}-\mathrm{PET}$ or ASL (PMROxASL). Changes in metabolism were investigated by increasing the propofol infusion to $20 \mathrm{~mL} / \mathrm{kg} / \mathrm{h}$.

Results: Good agreement and correlation were observed between regional $\mathrm{CMRO}_{2}$ measurements from PMROx and PET-alone. No significant differences were found between OxFlow and PETonly measurements of WB oxygen extraction fraction $(0.30 \pm 0.09$ and $0.31 \pm 0.09)$ and CBF $(54.1 \pm 16.7$ and $56.6 \pm 21.0 \mathrm{~mL} / 100 \mathrm{~g} / \mathrm{min})$, or between PMROx and PET-only $\mathrm{CMRO}_{2}$ estimates $\left(1.89 \pm 0.16\right.$ and $\left.1.81 \pm 0.10 \mathrm{mLO}_{2} / 100 \mathrm{~g} / \mathrm{min}\right)$. Moreover, PMROx and PMROxAsL were sensitive to propofol-induced reduction in $\mathrm{CMRO}_{2}$. 
Conclusion: This study provides initial validation of a noninvasive PET/MRI technique that circumvents many of the complexities of PET $\mathrm{CMRO}_{2}$ imaging. PMROx does not require arterial sampling and has the potential to reduce PET imaging to ${ }^{15} \mathrm{O}-\mathrm{O}_{2}$ only; however, future validation involving human participants are required.

\section{Keywords}

Cerebral blood flow; cerebral metabolic rate of oxygen; noninvasive PET; oxygen extraction fraction; PET/MRI 


\section{INTRODUCTION}

Positron emission tomography (PET) imaging of cerebral oxidative metabolism was developed over thirty years ago and continues to prove a vital tool for understanding brain energetics and the role of altered metabolism in disease processes (1-3). PET remains the gold standard for imaging the cerebral metabolic rate of oxygen $\left(\mathrm{CMRO}_{2}\right)$; however, the original procedure is complex and long (4). In addition to radiolabelled oxygen, ${ }^{15} \mathrm{O}-\mathrm{H}_{2} \mathrm{O}$ is needed to measure cerebral blood flow $(\mathrm{CBF})$ and ${ }^{15} \mathrm{O}-\mathrm{CO}$ to measure the cerebral blood volume (CBV). Arterial blood sampling is required for each tracer, along with separating plasma and red blood cell activity for ${ }^{15} \mathrm{O}_{-} \mathrm{O}_{2}$ to account for the increasing signal contribution from metabolically generated ${ }^{15} \mathrm{O}-\mathrm{H}_{2} \mathrm{O}$ (recirculating water, RW). Efforts to reduce its complexity and duration have led to modelling approaches that eliminate the need for separate CBV imaging and estimating RW without separating blood samples (5). Alternately, the effects of RW can be minimized by short scan times following a single inhalation of ${ }^{15} \mathrm{O}-\mathrm{O}_{2}(6)$. More recently, approaches incorporating image-derived input functions have been proposed to avoid measuring the arterial input function (AIF), which is an invasive and inherently noisy procedure $(7,8)$. However, the accuracy of these approaches depends on either an empirical factor relating the total AIF and its RW component, or careful measurement of a coefficient to scale the arterial time-activity curve (TAC).

We propose an alternative method to reduce the complexity, invasiveness, and duration of $\mathrm{CMRO}_{2}$ imaging (9). Similar to $\mathrm{Su}$ et al. (8), this method takes advantage of simultaneous PET/MRI. However, rather than attempting to use MRI to help extract the AIF, the proposed hybrid approach incorporates complementary MRI techniques to measure whole-brain (WB) $\mathrm{CMRO}_{2}$ to serve as a reference to calibrate dynamic ${ }^{15} \mathrm{O}$-oxygen PET data. Analogous to a similar PET/MR technique for imaging CBF (10), this hybrid approach eliminates the need for arterial 
sampling. Here, we implemented this reference-based approach, hereafter referred as PMROx (PET/MR imaging of oxidative metabolism), on a $3 \mathrm{~T}$ PET/MR scanner. The aim of this study is to validate PMROx in a large animal model by comparing to a previously validated dual-basis function method (DBFM) (11). In addition, we investigated if PMROx could be further simplified by incorporating CBF images from the MRI-based technique arterial spin labelling (ASL). This modification reduces PET imaging to only ${ }^{15} \mathrm{O}-\mathrm{O}_{2}$ and imaging duration to approximately $5 \mathrm{~min}$ since the MRI sequences can be run during the PET acquisition (12). In addition to validating PMROx, its sensitivity to changes in metabolism was investigated by altering the anesthetics administered to the animals. 


\section{MATERIALS AND METHODS}

Animal experiments were conducted according to the regulations of the Canadian Council of Animal Care and approved by the Animal Care Committee at Western University. Prior to imaging, juvenile Duroc pigs were tracheotomized, and catheters inserted into the cephalic veins and femoral arteries. During imaging, animals were mechanically ventilated, immobilized on a custom platform, and anesthetized with $3 \%$ isoflurane and $6 \mathrm{~mL} / \mathrm{kg} / \mathrm{h}$ propofol. Blood samples were collected to measure the partial pressures of oxygen and carbon dioxide, plasma glucose concentration, hematocrit, and hemoglobin concentration. Throughout the experiment, end-tidal $\mathrm{O}_{2}$ and $\mathrm{CO}_{2}$, temperature, heart rate, and oxygen saturation were monitored to ensure normal levels.

\section{Study Protocol}

PET and MRI data were obtained on a 3 T Siemens Biograph mMR system using a 12channel PET-compatible receiver head coil (Siemens GmbH). Each experiment was divided into two parts. First, the accuracy of PMROx was evaluated by comparing to the DBFM, which required measuring the AIFs of ${ }^{15} \mathrm{O}-\mathrm{H}_{2} \mathrm{O}$ and ${ }^{15} \mathrm{O}-\mathrm{O}_{2}$. Next, the sensitivity of PMROx to the expected reduction in cerebral metabolism was assessed by increasing the infusion rate of propofol to $20 \mathrm{~mL} / \mathrm{kg} / \mathrm{h}$ to induce a lower metabolic condition (LMC).

In both parts, PET imaging involved injecting ${ }^{15} \mathrm{O}-\mathrm{H}_{2} \mathrm{O}$ to measure $\mathrm{CBF}$, followed by inhalation of ${ }^{15} \mathrm{O}-\mathrm{O}_{2}$ to measure OEF. Concurrently, WB $\mathrm{CMRO}_{2}$ was obtained by the MRIsequence OxFlow (13), which combines phase-contrast MRI measurements of CBF from the internal carotid and basilar arteries, with venous oxygen saturation $\left(\mathrm{S}_{\mathrm{v}} \mathrm{O}_{2}\right)$ measurements from the superior sagittal sinus acquired with susceptibility-based oximetry (14). CBF images were collected using pseudo-continuous ASL (pCASL). At the end of experiment, the animal was 
euthanized according to the animal care guidelines and transported to a CT scanner to obtain a post-mortem CT-based attenuation correction map.

\section{PET Imaging and Postprocessing}

The PET protocol (Fig. 1) began with injecting ${ }^{15} \mathrm{O}-\mathrm{H}_{2} \mathrm{O}(460 \pm 80 \mathrm{MBq}$; cephalic vein), followed by inhaling $2,200 \mathrm{MBq}$ of ${ }^{15} \mathrm{O}-\mathrm{O}_{2}$. All acquisitions involved 5 min of list-mode acquisition. For DBFM, AIFs from ${ }^{15} \mathrm{O}-\mathrm{H}_{2} \mathrm{O}\left(C_{a}^{w}(t)\right)$ and ${ }^{15} \mathrm{O}-\mathrm{O}_{2}\left(C_{a}^{o}(t)\right)$ were determined by withdrawing blood from a femoral artery and measuring the activity using an MR-compatible system (Swisstrace $\mathrm{GmbH}) .{ }^{15} \mathrm{O}_{-} \mathrm{O}_{2}-\mathrm{PET}$ data acquisition during the LMC started approximately 1 hour after the first ${ }^{15} \mathrm{O}-\mathrm{O}_{2}$ acquisition to allow the animal to stabilize after changing the anaesthetics.

${ }^{15} \mathrm{O}-\mathrm{H}_{2} \mathrm{O}$ and ${ }^{15} \mathrm{O}-\mathrm{O}_{2}$ were produced by $(\mathrm{d}, \mathrm{n}){ }^{14} \mathrm{~N}$ reaction in an onsite cyclotron (PETtrace 800, 16.5 MeV; GE Healthcare) (15). For ${ }^{15} \mathrm{O}-\mathrm{O}_{2}$ imaging, the radioactive gas was filtered prior to being transferred to the PET/MR suite via a stainless-steel line (202-m long, 3-mm diameter). The line was connected to polyethylene tubing that directly fed into the inhalation tube of the animal (delivery rate of $1.5 \mathrm{~L} / \mathrm{min}$ for $30 \mathrm{~s}$ ). Expired gas was collected in a 200 -L tank to hold it for seven half-lives (16).

Dynamic PET images were reconstructed into 48 time-frames $(30 \times 3 \mathrm{~s}, 6 \times 5 \mathrm{~s}, 6 \times 10 \mathrm{~s}$ and $6 \times 20 \mathrm{~s}$ ) using the Siemens e7-tools suite with a 3D-OSEM method (iterations/subsets, 4/21; matrix size, $344 \times 344 \times 127$ voxels; field of view $\left[\right.$ FoV], $359 \times 359 \times 258 \mathrm{~mm}^{3}$; voxel size, $1 \times 1 \times 2 \mathrm{~mm}^{3}$; zoom factor, 2). Raw data were corrected for decay, random incidences, dead-time, detector normalization, data rebinning, and scatter. Absolute scatter correction was used for the ${ }^{15} \mathrm{O}-\mathrm{O}_{2}$ 
images, as recommended for 3D scanning (17). Reconstructed images were smoothed by a 4-mm Gaussian filter.

AIFs were decay corrected, and denoised using a wavelet signal denoising function (MATLAB R2017b, Block James-Stein method). The RW $\left(A_{w}(t)\right)$ component of the measured ${ }^{15} \mathrm{O}_{-} \mathrm{O}_{2}$ AIF was estimated using species-specific values after interpolating to the differences in weight (18).

\section{MR Imaging and Postprocessing}

MR acquisition (Supplemental Fig. 1) began with T1-weighted images (magnetizationprepared rapid gradient-echo sequence, MPRAGE; repetition/echo/inversion times [TR/TE/TI], 2,000/2.98/900 ms; flip angle [ $\alpha], 9^{\circ} ; \mathrm{FoV}, 256 \times 256 \mathrm{~mm}^{2} ; 176$ slices; isotropic voxel size, $1 \mathrm{~mm}^{3}$ ), followed by time-of-flight images to identify the feeding arteries for phase-contrast imaging (TR/TE, 22/3.75 ms; $\alpha, 18^{\circ}$; FoV, $200 \times 181 \mathrm{~mm}^{2} ; 102$ slices; voxel size, $0.3 \times 0.3 \times 1.5 \mathrm{~mm}^{3} ; 40 \mathrm{~mm}$ saturation band) and the sagittal sinus for oximetry imaging (no saturation band).

MR images acquired during PET acquisitions were OxFlow and pCASL. The former alternates between the two slice locations to measure WB CBF and $\mathrm{S}_{\mathrm{v}} \mathrm{O}_{2}(\mathrm{TR} / \mathrm{TE} / \Delta \mathrm{TE}$, $35 / 7.025 / 2.5 \mathrm{~ms} ; \alpha, 25^{\circ} ; \mathrm{FoV}, 208 \times 208 \mathrm{~mm}^{2}$; voxel size, $1.6 \times 1.6 \times 5.0 \mathrm{~mm}^{3}$; velocity encoding [VENC], $60 \mathrm{~cm} / \mathrm{s}$; acquisition time, $1 \mathrm{~min}$ ) (13). The acquisition of the OxFlow sequence was timed to coincide with the ${ }^{15} \mathrm{O}-\mathrm{O}_{2}$ imaging and the resultant images represent an average over the 1-min scan to provide a stable reference measurement. Immediately following, a 3-dimensional pCASL sequence was run (19) (TR/TE, 3,720/22.9 ms; FoV, 208 $\times 208 \mathrm{~mm}^{2}$; 16 slices; voxel size, $3.3 \times 3.3 \times 5.0 \mathrm{~mm}^{3}$; post-labelling delay/labelling duration, $1500 / 1800 \mathrm{~ms}$; label plane offset, 
$60 \mathrm{~mm} ; 16$ measurements). Lastly, proton density-weighted images were acquired by turning off the labelling or background suppression pulses ( $\left.\mathrm{M}_{0} ; \mathrm{TR}, 7,000 \mathrm{~ms}\right)$.

OxFlow images were analyzed following the approach outlined by Jain et al. (14). Briefly, regions-of-interest were semi-automatically drawn in and surrounding the vessels on the magnitude image, then transferred to the phase image to measure the mean phase difference in the feeding arteries, and between the sagittal sinus and the surrounding tissue. The pCASL images were motion corrected, coregistered to $\mathrm{M}_{0}$, and smoothed with a 4-mm Gaussian filter. $\mathrm{CBF}$ images were generated using the standard one-compartment model (12). For this analysis, the blood-brain partition coefficient of water was $0.90 \mathrm{~mL} / \mathrm{g}$, the longitudinal relaxation time of blood was $1.65 \mathrm{~s}$, and the labelling efficiency was assumed to be 0.86 . Images were coregistered to the PET space using SPM12 (https://www.fil.ion.ucl.ac.uk/spm/).

\section{PET-Only Imaging: DBFM}

CBF $\left(f_{i}\right)$ maps were generated from ${ }^{15} \mathrm{O}-\mathrm{H}_{2} \mathrm{O}-\mathrm{PET}$ by fitting the following equation to the local TACs $\left(C_{i}(t)\right)$ :

$$
C_{i}(t)=f_{i} \cdot C_{a}^{w}(t) * e^{-k_{2 i} t}+V_{b_{i}}^{w} \cdot C_{a}^{w}(t)
$$

where $*$ represents convolution. The fitting parameters were $k_{2_{i}}$ (clearance rate constant), $f_{i}$, and $V_{b_{i}}^{w}$ (arterial blood volume). OEF $\left(E_{i}\right)$ and $\mathrm{CMRO}_{2}$ measurements were obtained by fitting ${ }^{15} \mathrm{O}-\mathrm{O}_{2}$ PET data to Eq. (2) (11).

$$
C_{i}(t)=E_{i} \cdot f_{i} \cdot A_{o}(t) * e^{-k_{2 i} t}+f_{i} \cdot A_{w}(t) * e^{-k_{2 i} t}+V_{0_{i}}^{o} \cdot A_{o}(t)+V_{A_{i}}^{w} \cdot A_{w}(t)
$$


where $A_{o}(t)$ is the ${ }^{15} \mathrm{O}-\mathrm{O}_{2}$ component of the AIF. The fitting parameters were $E_{i}, V_{0_{i}}^{o}$ and $V_{A_{i}}^{w}{ }^{15} \mathrm{O}-$ $\mathrm{O}_{2}$ and ${ }^{15} \mathrm{O}-\mathrm{H}_{2} \mathrm{O}$ blood volumes, respectively). All fitting was performed in MATLAB using the optimization routine fmincon. $\mathrm{CMRO}_{2}$ was calculated from Fick's principle as $C M R O_{2_{i}}=E_{i} \cdot f_{i}$. $\mathrm{C}_{a} \mathrm{O}_{2}$, where $\mathrm{C}_{a} \mathrm{O}_{2}=1.34 \cdot \mathrm{Hb} \cdot \mathrm{S}_{a} \mathrm{O}_{2}+0.003 \cdot \mathrm{P}_{a} \mathrm{O}_{2}, \mathrm{Hb}$ is the hemoglobin concentration, and $\mathrm{S}_{a} \mathrm{O}_{2}$ (arterial saturation of oxygen) was estimated using the $\mathrm{P}_{a} \mathrm{O}_{2}$ (partial pressure of oxygen) measurements (20). Please refer to the Supplemental Data for a glossary of variables.

\section{PMROx}

PMROx $\mathrm{CMRO}_{2}$ images were generated from ${ }^{15} \mathrm{O}_{-} \mathrm{O}_{2}$-PET data using Eq. (3), which was derived from the one-tissue compartment model (9).

$$
C M R O_{2_{i}}=C M R O_{2_{w b}}\left[\frac{\int_{0}^{T} C_{i}(t) d t+\frac{f_{i}}{p} \int_{0}^{T} \int_{0}^{t} C_{i}(u) d u d t}{\int_{0}^{T} C_{w b}(t) d t+\frac{f_{w b}}{p} \int_{0}^{T} \int_{0}^{t} C_{w b}(u) d u d t}\right]
$$

where $T$ is scan time. Local OEF was calculated by $E_{i}=C M R O_{2} /\left(f_{i} \cdot C_{a} O_{2}\right)$. Both $f_{w b}$ and $\mathrm{CMRO}_{2}$ were obtained from OxFlow, the latter by:

$$
\mathrm{CMRO}_{2_{w b}}=\mathrm{C}_{a} \mathrm{O}_{2} \cdot f_{w b}\left(\frac{S_{a} \mathrm{O}_{2}-S_{v} \mathrm{O}_{2}}{S_{a} O_{2}}\right)
$$

CBF (Eq. (5)) was obtained using the noninvasive PET/MR approach described by Ssali et al. (10), in which WB CBF is used to calibrate ${ }^{15} \mathrm{O}-\mathrm{H}_{2} \mathrm{O}-\mathrm{PET}$ data. In both Eqs. (3) and (5), WB $\mathrm{CMRO}_{2}, \mathrm{CBF}$, and $\mathrm{TAC}$ are used as scalers to obtain the corresponding local values. Alternatively for $\mathrm{CBF}$, a direct scaling approach could be implemented (21). 


$$
f_{i}=\frac{\int_{0}^{T} C_{i}(t) d t}{\frac{1}{f_{w b}} \int_{0}^{T} C_{w b}(t) d t+\frac{1}{p}\left(\int_{0}^{T} \int_{0}^{t} C_{w b}(u) d u d t-\int_{0}^{T} \int_{0}^{t} C_{i}(u) d u d t\right)}
$$

The feasibility of implementing pCASL into the PMROx approach (PMROxASL) was also evaluated. In this case, $f_{i}$ in Eq. (3) was obtained from the CBF images generated by pCASL.

\section{Regional CBF, OEF and $\mathrm{CMRO}_{2}$ Measurements}

Volumes-of-interest (VOIs) were semi-automatically drawn on the MPRAGE images for each animal and then transferred to the corresponding $\mathrm{CBF}, \mathrm{OEF}$ and $\mathrm{CMRO}_{2}$ images. Measurements were made for cerebellum $\left(4.2 \pm 0.7 \mathrm{~cm}^{3}\right)$, diencephalon $\left(4.7 \pm 0.6 \mathrm{~cm}^{3}\right)$, and frontal $\left(2.4 \pm 0.6 \mathrm{~cm}^{3}\right)$, occipital $\left(7.9 \pm 1.5 \mathrm{~cm}^{3}\right)$, parietal $\left(9.1 \pm 1.6 \mathrm{~cm}^{3}\right)$ and temporal $\left(6.0 \pm 0.6 \mathrm{~cm}^{3}\right)$ lobes. All images were registered to the anatomical image of one animal to generate group-wise maps using SPM12 (https://www.fil.ion.ucl.ac.uk/spm/).

\section{Statistics}

Local measurements were compared using linear regression to obtain the Pearson correlation coefficient $(\rho)$. Any potential bias was assessed using a one-sample $t$-test. Paired $t$-tests were performed to evaluate differences between measurements. Statistical significance was defined by $P<0.05$ and Bonferroni correction was performed when necessary. Measurements are expressed in terms of mean \pm standard deviation. Statistical tests were performed using SPSS (v26, https://www.ibm.com/analytics/spss-statistics-software). 


\section{RESULTS}

Data from nine juvenile pigs were collected (age range 8-10 weeks; weight, $19 \pm 2 \mathrm{~kg}$; 5 female). In one experiment, only ${ }^{15} \mathrm{O}-\mathrm{H}_{2} \mathrm{O}$ data were acquired due to a technical issue with the ${ }^{15} \mathrm{O}$ oxygen line. The LMC was successfully induced in six animals. Supplemental Table 1 provides a summary of arterial blood measurements during baseline and LMC.

AIFs could not be acquired in three cases (one ${ }^{15} \mathrm{O}-\mathrm{H}_{2} \mathrm{O}$ and two ${ }^{15} \mathrm{O}-\mathrm{O}_{2}$ ) due to clotting of the sampling line. In these cases, population-based AIFs were used after using a scaling factor for each animal individually. For the ${ }^{15} \mathrm{O}-\mathrm{H}_{2} \mathrm{O}$ case, the AIF was scaled by the injected dose (MBq). Since the administered activity was unknown for $\left[{ }^{15} \mathrm{O}\right] \mathrm{O}_{2}$, the AIF was scaled to the mean jaw muscle activity $\left(C_{m}\right)$ measured from a $50-\mathrm{mm}^{2} \mathrm{ROI}$. The appropriate scaling factor was determined by a combination of principal component and multiple linear regression analyses involving the remaining 6 measured AIFs. The factors included body weight (kg), endotracheal tube peak activity $(\mathrm{kBq} / \mathrm{mL})$, mean jaw muscle activity concentration $(\mathrm{kBq} / \mathrm{mL})$, and partial pressure of carbon dioxide (mmHg). The resulting model equation was subsequently used to scale the population-based AIF for each animal. Principal component analysis and multiple linear regression identified mean jaw muscle activity concentration $\left(C_{m}\right)$ as significant component for estimating the scaling factor of ${ }^{15} \mathrm{O}_{-} \mathrm{O}_{2}\left(=43.5 \cdot C_{m} ; R^{2}=0.998\right)$. Supplemental Figure 2 presents a comparison between ${ }^{15} \mathrm{O}-\mathrm{O}_{2}$ measured AIFs with their respective scaled population-based curves; the blue curves represent the population-based AIFs used for the two animals that arterial sampling failed. 


\section{Validation}

Average WB estimates of $\mathrm{CBF}, \mathrm{OEF}$ and $\mathrm{CMRO}_{2}$ from PET and PET/MR were in good agreement with no significant differences between techniques: $56.6 \pm 21.0 \mathrm{~mL} / 100 \mathrm{~g} / \mathrm{min}$, $0.31 \pm 0.09$, and $1.81 \pm 0.10 \mathrm{mLO}_{2} / 100 \mathrm{~g} / \mathrm{min}$ from $\mathrm{DBFM}$ and $54.1 \pm 16.7 \mathrm{~mL} / 100 \mathrm{~g} / \mathrm{min}$ $0.30 \pm 0.09$ and $1.89 \pm 0.16 \mathrm{mLO}_{2} / 100 \mathrm{~g} / \mathrm{min}$ from OxFlow/PMROx, respectively. Average WB$V_{b}^{w}$ from ${ }^{15} \mathrm{O}-\mathrm{H}_{2} \mathrm{O}-\mathrm{PET}$ was $9.5 \pm 4.0 \mathrm{~mL} / 100 \mathrm{~g}$, and $\mathrm{WB} V_{0}^{o}$ and $V_{A}^{w}$ values from ${ }^{15} \mathrm{O}-\mathrm{O}_{2}-\mathrm{PET}$ were $7.0 \pm 1.0 \mathrm{~mL} / 100 \mathrm{~g}$ and $2.6 \pm 6.7 \mathrm{~mL} / 100 \mathrm{~g}$, respectively. WB $V_{A}^{w}$ was small $(<2 \mathrm{~mL} / 100 \mathrm{~g})$ for 7 of 8 animals; however, in one outlier it was $19.1 \mathrm{~mL} / 100 \mathrm{~g}$.

Regional results of regression and correlation (Fig. 2) analyses from CBF, OEF and $\mathrm{CMRO}_{2}$ measurements are summarized in Table 1. Significant correlations between regional CBF estimates from noninvasive PET/MR and DBFM were observed in all VOIs. The Bland-Altman plot indicated a bias in local CBF measurements by noninvasive PET/MR for the parietal lobe $(7.7 \mathrm{~mL} / 100 \mathrm{~g} / \mathrm{min}, \quad P=0.02)$ and diencephalon $(14.8 \mathrm{~mL} / 100 \mathrm{~g} / \mathrm{min}, \quad P=0.02)$. Strong correlations between regional OEF estimates from PMROx and DBFM were observed (Fig. 2B and 3). Finally, regression between $\mathrm{CMRO}_{2}$ estimates from the two techniques revealed good agreement with a moderate correlation and a small bias in the PMROx measurements for the cerebellum $\left(0.16 \mathrm{mLO}_{2} / 100 \mathrm{~g} / \mathrm{min}, P=0.03\right)$ and diencephalon $\left(0.30 \mathrm{mLO}_{2} / 100 \mathrm{~g} / \mathrm{min}, P<0.01\right)$.

\section{PMROx $x_{\text {ASL }}$}

Average WB estimates of $\mathrm{CBF}$ and $\mathrm{CMRO}_{2}$ from pCASL and PMROxASL were $58.6 \pm 20.4 \mathrm{~mL} / 100 \mathrm{~g} / \mathrm{min}$ and $1.88 \pm 0.24 \mathrm{mLO}_{2} / 100 \mathrm{~g} / \mathrm{min}$, respectively, which were not significantly different from the PET-only results. Regional measurements were successfully extracted from all VOIs (Table 1, Fig. 3 and 4), except for the cerebellum from one animal because 
this region was missing in the pCASL FoV. Strong correlations between DBFM and pCASL CBF estimates were observed, as well as between DBFM and PMROxASL OEF estimates with a small bias in the temporal lobe $(-0.048, P=0.02) . \mathrm{CMRO}_{2}$ values from PMROxASL and DBFM showed a moderate correlation.

\section{Lower Metabolic Condition}

For the six animals in which measurements were acquired under both conditions, propofol caused WB CBF to decrease to $27.3 \pm 7.0$ and $29.9 \pm 6.4 \mathrm{~mL} / 100 \mathrm{~g} / \mathrm{min}$ for OxFlow and pCASL, respectively (50\% reduction; Fig. 3 and 5A). There was a corresponding significant increase in OEF of $0.11 \pm 0.06$ (Fig. 5B) measured by OxFlow, and a significant reduction in WB-CMRO 2

measured by PMROx and PMROxASL of $0.68 \pm 0.36$ and $0.67 \pm 0.36 \mathrm{mLO}_{2} / 100 \mathrm{~g} / \mathrm{min}$, respectively; (Fig. 3 and 5C). 


\section{DISCUSSION}

${ }^{15} \mathrm{O}-\mathrm{O}_{2}-\mathrm{PET}$ has been used extensively to assess disruptions in cerebral energy metabolism, such as following stroke, predicting its risk of recurrence, and understanding energy regulation during functional activation (22). Despite the proven value of ${ }^{15} \mathrm{O}-\mathrm{O}_{2}-\mathrm{PET}$, the procedure is complex and invasive, which has led to a diminishing number of sites with the necessary expertise to conduct ${ }^{15} \mathrm{O}-\mathrm{O}_{2}$ studies. This trend highlights the value to develop simpler ${ }^{15} \mathrm{O}-\mathrm{O}_{2}$ imaging protocols that retain the inherent quantitative capabilities of PET. This study focused on validating a hybrid PET/MR technique developed specifically to address this issue. The possibility of using PET/MR to update ${ }^{15} \mathrm{O}_{-} \mathrm{O}_{2}$ imaging was investigated by Su et al., who used MRI to extract imagederived AIFs (8). The current study explored an alternative approach using WB MRI measurements as a reference, which avoids potential registration and partial volume errors. PMROx is also less sensitive to errors caused by $\mathrm{RW}$ and the $\mathrm{CBV}$ since regional $\mathrm{CMRO}_{2}$ is determined from the ratio of TACs.

Validation experiments were conducted using a porcine model and involved imaging $\mathrm{CMRO}_{2}$ independently using the previously validated DBFM (11). For this method, an MRcompatible arterial sampling system was used to measure the AIF for both tracers. Good agreement between PMROx and DBFM was found across VOIs with respect to both OEF and $\mathrm{CMRO}_{2}$, although a small bias was observed in the PMROx $\mathrm{CMRO}_{2}$ estimates (Fig. 2F). Regression analysis also demonstrated strong and moderate correlations between techniques for OEF and $\mathrm{CMRO}_{2}$, respectively. The lower correlation for the latter is explained by its dependency on both OEF and CBF. In addition to the agreement with DBFM, PMROx was shown to be sensitive to reduced energy metabolism caused by increasing the propofol infusion. The $\mathrm{CMRO}_{2}$ reduction was driven by the propofol-induced decrease in CBF, since propofol caused an increase in OEF. 
These findings are in agreement with Oshima et al. who reported that propofol caused proportional decreases in $\mathrm{CBF}$ and $\mathrm{CMRO}_{2}$, but had no effect on the arteriovenous oxygen difference (23).

Since the PMROx approach scales the ${ }^{15} \mathrm{O}_{-} \mathrm{O}_{2}$ images by an MRI estimate of $\mathrm{WB} \mathrm{CMRO}_{2}$, its accuracy and precision will be directly affected by the MRI methods used to calculate WB OEF and CBF. In this study, WB OEF and $\mathrm{CMRO}_{2}$ were measured by OxFlow, which can be acquired

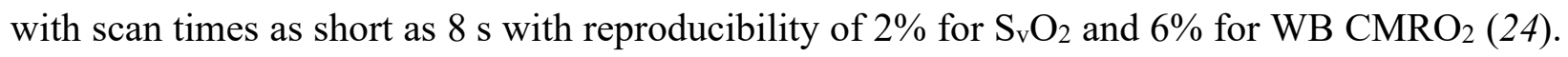
The accuracy of OxFlow depends on positioning the slices orthoganal to the main magnetic field, correcting for magnetic field inhomogeneities, and using sufficient image resolution to avoid partial volume effects (13). The current study presents the first simultaneous comparison of OxFlow to ${ }^{15} \mathrm{O}-\mathrm{H}_{2} \mathrm{O}$ and ${ }^{15} \mathrm{O}-\mathrm{O}_{2}$ PET, and no significant differences were found between techniques. This agreement is in accordance with two recent studies comparing MR measurements of $\mathrm{S}_{\mathrm{v}} \mathrm{O}_{2}$ to either PET or direct measures from the jugular blub $(25,26)$.

PET/MR also provides the possibility of reducing the PET procedure to just ${ }^{15} \mathrm{O}_{-} \mathrm{O}_{2}$ inhalation by replacing ${ }^{15} \mathrm{O}-\mathrm{H}_{2} \mathrm{O}-\mathrm{PET}$ with ASL (PMROxASL). WB CBF estimates from pCASL were in good agreement to those obtained by ${ }^{15} \mathrm{O}-\mathrm{H}_{2} \mathrm{O}-\mathrm{PET}$, similar to previous ASL/PET comparisons conducted using a swine model $(10,27)$. Strong correlations between regional CBF measurements were found for all VOIs except the cerebellum, which was attributed to limited spatial coverage for the pCASL sequence. Recent studies comparing ASL to PET involving human participants indicate that ASL can provide accurate CBF measurements with careful attention to common sources of error (28), including low signal-to-noise ratio and sensitivity to transit times (29). Consequently, translation to clinical studies remains an active area of research as factors such as cerebrovascular disease and ageing can impact its accuracy (30). 
A challenge with PET-only imaging is correcting for signal contamination from the CBV (4). Blood volume terms were incorporated into the fitting procedure for both tracers. Although the average $V_{b}^{w}$ was larger than reported in human studies, it is in accordance with Olsen et al. who reported values from 9 to $18 \mathrm{~mL} / 100 \mathrm{~g}$ in pigs, depending on partial pressures of carbon dioxide levels (31). The $V_{0}^{o}$ values were smaller since they are scaled by OEF and the venous fraction. WB $V_{A}^{w}$ estimates were very small for most animals, as expected, as it only becomes significant in highly vascularized regions $(11)$. In one animal, $V_{A}^{w}$ reached a non-physiological value, which was likely a result of estimating $A_{w}(t)$ using a physiologic model.

Although this study demonstrated the advantages of PET/MRI for imaging $\mathrm{CMRO}_{2}(32)$, this modality is not widely accessible and requires an onsite cyclotron for ${ }^{15} \mathrm{O}-\mathrm{O}_{2}$ production. A potential limitation with the current study was the indirect methods used to account for RW and $\mathrm{CBV}$ in the DBFM, rather than direct measurements; however, this approach has been previously validated (11). Lastly, Fig 2F indicates that the discrepancy between PMROx and DBFM increased as the difference between local and WB OEF values increased, which is attributed to neglecting RW by PMROx. It should be possible to reduce this error by incorporating a RW term in the model equation (9). 


\section{CONCLUSION}

This study presents the validation of a noninvasive hybrid PET/MR technique to image $\mathrm{CMRO}_{2}$ that requires a short inhalation of ${ }^{15} \mathrm{O}-\mathrm{O}_{2}$, followed by $5 \mathrm{~min}$ of PET and simultaneous MR imaging. Good agreement between $\mathrm{CMRO}_{2}$ values from PMROx and the DBFM was found, and the proposed method was shown to be sensitive to reduced cerebral metabolism induced by increasing the anaesthetic level. 


\section{DISCLOSURE}

This work was supported by the Canadian Institutes of Health Research, grant 148600 . There is no potential conflict of interest relevant to this article. 


\section{KEY POINTS}

QUESTION: Can the cerebral metabolic rate of oxygen $\left(\mathrm{CMRO}_{2}\right)$ be quantified using MRI functional measurements to calibrate ${ }^{15} \mathrm{O}_{-} \mathrm{O}_{2}-\mathrm{PET}$ ?

PERTINENT FINDINGS: The proposed PMROx approach resulted in $\mathrm{CMRO}_{2}$ values comparable to those obtained from a PET-only technique. PMROx was further simplified by incorporating ASL, and it proved sensitive to anaesthetics-induced changes in metabolism.

IMPLICATIONS FOR PATIENT CARE: PMROx is a noninvasive technique that requires only

${ }^{15} \mathrm{O}-\mathrm{O}_{2}$, which facilitates its application in human studies, and it may prove to be a useful tool to better understand disorders characterized by disruptions in the cerebral oxidative metabolism. 


\section{REFERENCES}

1. Lin W, Powers WJ. Oxygen metabolism in acute ischemic stroke. J Cereb Blood Flow Metab. 2018;38:1481-1499.

2. Vaishnavi SN, Vlassenko AG, Rundle MM, Snyder AZ, Mintun MA, Raichle ME. Regional aerobic glycolysis in the human brain. Proc Natl Acad Sci U S A. 2010;107:17757-62.

3. Baron JC, Jones T. Oxygen metabolism, oxygen extraction and positron emission tomography: Historical perspective and impact on basic and clinical neuroscience. Neuroimage. 2012;61:492-504.

4. Mintun MA, Raichle ME, Martin WR, Herscovitch P. Brain oxygen utilization measured with O-15 radiotracers and positron emission tomography. J Nucl Med. 1984;25:177-87.

5. Spees W, Yablonskiy D, Morris ED, et al. Feasibility of Using Arterial Spin Labeling for Detecting. J Cereb Blood Flow Metab. 2015;7:77.

6. Ohta S, Meyer E, Thompson CJ, Gjedde A. Oxygen consumption of the living human brain measured after a single inhalation of positron emitting oxygen. J Cereb Blood Flow Metab. $1992 ; 12: 179-192$.

7. Kudomi N, Maeda Y, Yamamoto H, Yamamoto Y, Hatakeyama T, Nishiyama Y. Reconstruction of input functions from a dynamic PET image with sequential administration of $15 \mathrm{O} 2$ and $\mathrm{H} 215 \mathrm{O}$ for noninvasive and ultra-rapid measurement of $\mathrm{CBF}$, OEF, and CMRO2. J Cereb Blood Flow Metab. 2018;38:780-792.

8. Su Y, Vlassenko AG, Couture LE, et al. Quantitative hemodynamic PET imaging using image-derived arterial input function and a PET/MR hybrid scanner. J Cereb Blood Flow Metab. 2017;37:1435-1446. 
9. Narciso L, Ssali T, Iida H, St Lawrence K. A non-invasive reference-based method for imaging the cerebral metabolic rate of oxygen by PET/MR: theory and error analysis. Phys Med Biol. February 2021.

10. Ssali T, Anazodo UC, Thiessen JD, Prato FS, St. Lawrence K. A noninvasive method for quantifying cerebral blood flow by hybrid PET/MRI. J Nucl Med. 2018;59:1329-1334.

11. Kudomi N, Hirano Y, Koshino K, et al. Rapid quantitative CBF and CMRO2 measurements from a single PET scan with sequential administration of dual 15O-labeled tracers. $J$ Cereb Blood Flow Metab. 2013;33:440-448.

12. Alsop DC, Detre JA, Golay X, et al. Recommended implementation of arterial spin-labeled perfusion MRI for clinical applications: A consensus of the ISMRM perfusion study group and the European consortium for ASL in dementia. Magn Reson Med. 2015;73:102-116.

13. Wehrli FW, Rodgers ZB, Jain V, et al. Time-resolved MRI oximetry for quantifying CMRO2 and vascular reactivity. Acad Radiol. 2014;21:207-214.

14. Jain V, Langham MC, Wehrli FW. MRI estimation of global brain oxygen consumption rate. J Cereb Blood Flow Metab. 2010;30:1598-1607.

15. Cockburn N, Corsaut J, Kovacs MS, St. Lawrence K, Hicks JW. Validation protocol for current good manufacturing practices production of [15O]water for hybrid PET/MR studies. Nucl Med Commun. 2020;41:1100-1105.

16. Iguchi S, Moriguchi T, Yamazaki M, et al. System evaluation of automated production and inhalation of 15O-labeled gaseous radiopharmaceuticals for the rapid 15O-oxygen PET examinations. EJNMMI Phys. 2018;5:1-21.

17. Hori Y, Hirano Y, Koshino K, et al. Validity of using a 3-dimensional PET scanner during 
inhalation of 15 O-labeled oxygen for quantitative assessment of regional metabolic rate of oxygen in man. Phys Med Biol. 2014;59:5593-5609.

18. Kudomi N, Hayashi $\mathrm{T}$, Watabe $\mathrm{H}$, et al. A physiologic model for recirculation water correction in CMRO2 assessment with $15 \mathrm{O} 2$ inhalation PET. J Cereb Blood Flow Metab. 2009;29:355-364.

19. Günther M, Oshio K, Feinberg DA. Single-shot 3D imaging techniques improve arterial spin labeling perfusion measurements. Magn Reson Med. 2005;54:491-498.

20. Severinghaus JW. Simple, accurate equations for human blood O2 dissociation computations. J Appl Physiol. 1979;46:599-602.

21. Ishii Y, Thamm T, Guo J, et al. Simultaneous phase-contrast MRI and PET for noninvasive quantification of cerebral blood flow and reactivity in healthy subjects and patients with cerebrovascular disease. J Magn Reson Imaging. 2020;51:183-194.

22. Vafaee MS, Vang K, Bergersen LH, Gjedde A. Oxygen consumption and blood flow coupling in human motor cortex during intense finger tapping: Implication for a role of lactate. J Cereb Blood Flow Metab. 2012;32:1859-1868.

23. Oshima T, Karasawa F, Satoh T. Effects of propofol on cerebral blood flow and the metabolic rate of oxygen in humans. Acta Anaesthesiol Scand. 2002;46:831-835.

24. Barhoum S, Langham MC, Magland JF, et al. Method for rapid MRI quantification of global cerebral metabolic rate of oxygen. J Cereb Blood Flow Metab. 2015;35:1616-1622.

25. Miao X, Nayak KS, Wood JC. In vivo validation of T2- and susceptibility-based SvO2 measurements with jugular vein catheterization under hypoxia and hypercapnia. Magn Reson Med. 2019;82:2188-2198. 
26. Jiang D, Deng S, Franklin CG, et al. Validation of T2-based oxygen extraction fraction measurement with 150 positron emission tomography. Magn Reson Med. 2021;85:290-297.

27. Andersen JB, Henning WS, Lindberg U, et al. Positron emission tomography/magnetic resonance hybrid scanner imaging of cerebral blood flow using 15O-water positron emission tomography and arterial spin labeling magnetic resonance imaging in newborn piglets. J Cereb Blood Flow Metab. 2015;35:1703-1710.

28. Puig O, Henriksen OM, Vestergaard MB, et al. Comparison of simultaneous arterial spin labeling MRI and 15O-H2O PET measurements of regional cerebral blood flow in rest and altered perfusion states. J Cereb Blood Flow Metab. 2020;40:1621-1633.

29. Wu WC, St Lawrence KS, Licht DJ, Wang DJJ. Quantification issues in arterial spin labeling perfusion magnetic resonance imaging. Top Magn Reson Imaging. 2010;21:65-73.

30. Fan AP, Jahanian H, Holdsworth SJ, Zaharchuk G. Comparison of cerebral blood flow measurement with [150]-water positron emission tomography and arterial spin labeling magnetic resonance imaging: A systematic review. J Cereb Blood Flow Metab. 2015;36:842-861.

31. Olsen AK, Keiding S, Munk OL. Effect of hypercapnia on cerebral blood flow and blood volume in pigs studied by positron emission tomography. Comp Med. 2006;56:416-420.

32. Fan AP, An H, Moradi F, et al. Quantification of brain oxygen extraction and metabolism with [15O]-gas PET: A technical review in the era of PET/MRI. Neuroimage. 2020;220:117136. 


\section{FIGURE LEGENDS}

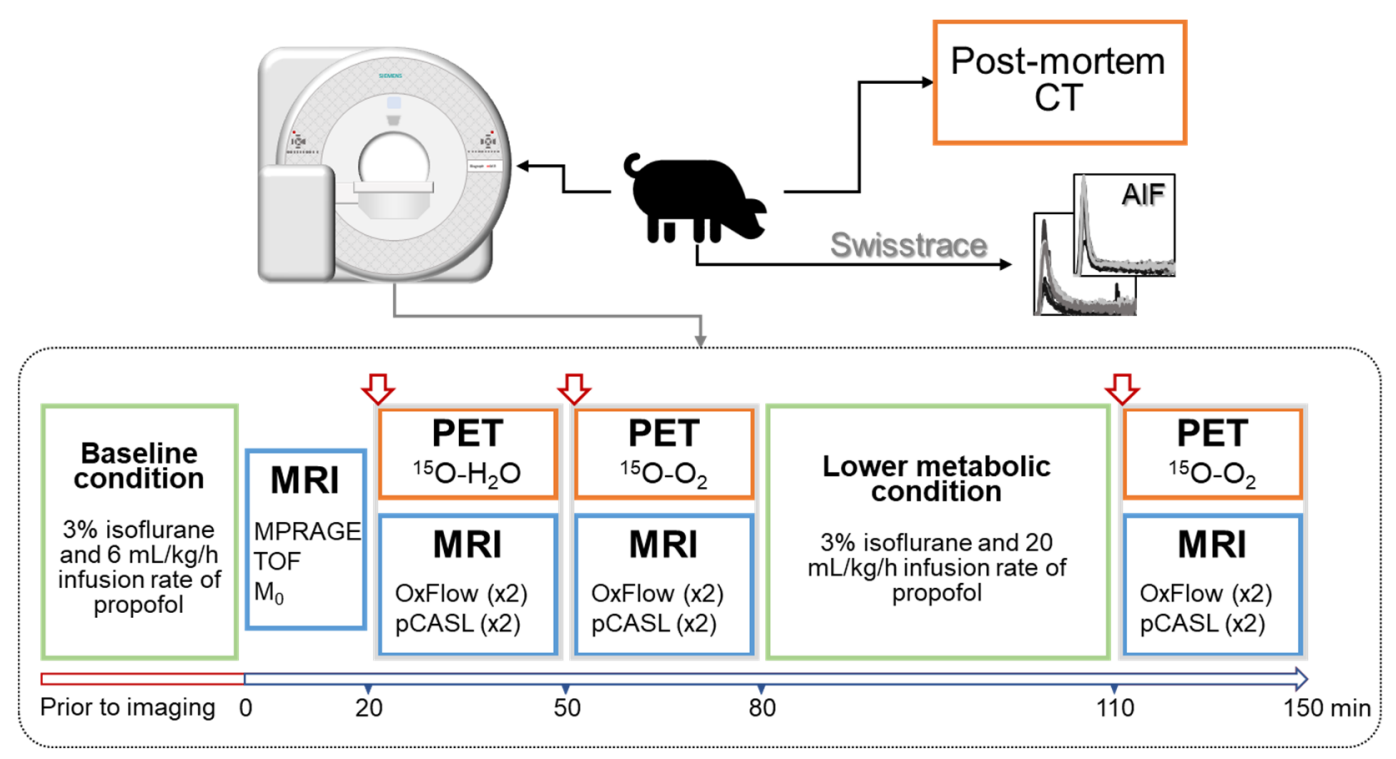

FIGURE 1. Protocol diagram showing the imaging blocks acquired at baseline and under the lower metabolic condition. Prior to imaging, the animal was positioned in the scanner and the anesthetics was applied. At time zero, MR imaging was started, and the onsite cyclotron was contacted to produce the ${ }^{15} \mathrm{O}-$ $\mathrm{H}_{2} \mathrm{O}$ dose, which was injected at the 20 min mark. There was a delay of approximately 20 min prior to ${ }^{15} \mathrm{O}-$ $\mathrm{O}_{2}$ delivery. Following the first ${ }^{15} \mathrm{O}_{-} \mathrm{O}_{2}$ imaging block, the propofol infusion rate was increased to $20 \mathrm{~mL} / \mathrm{kg} / \mathrm{h}$. The second ${ }^{15} \mathrm{O}-\mathrm{O}_{2}$ run was performed at $110 \mathrm{~min}$. 

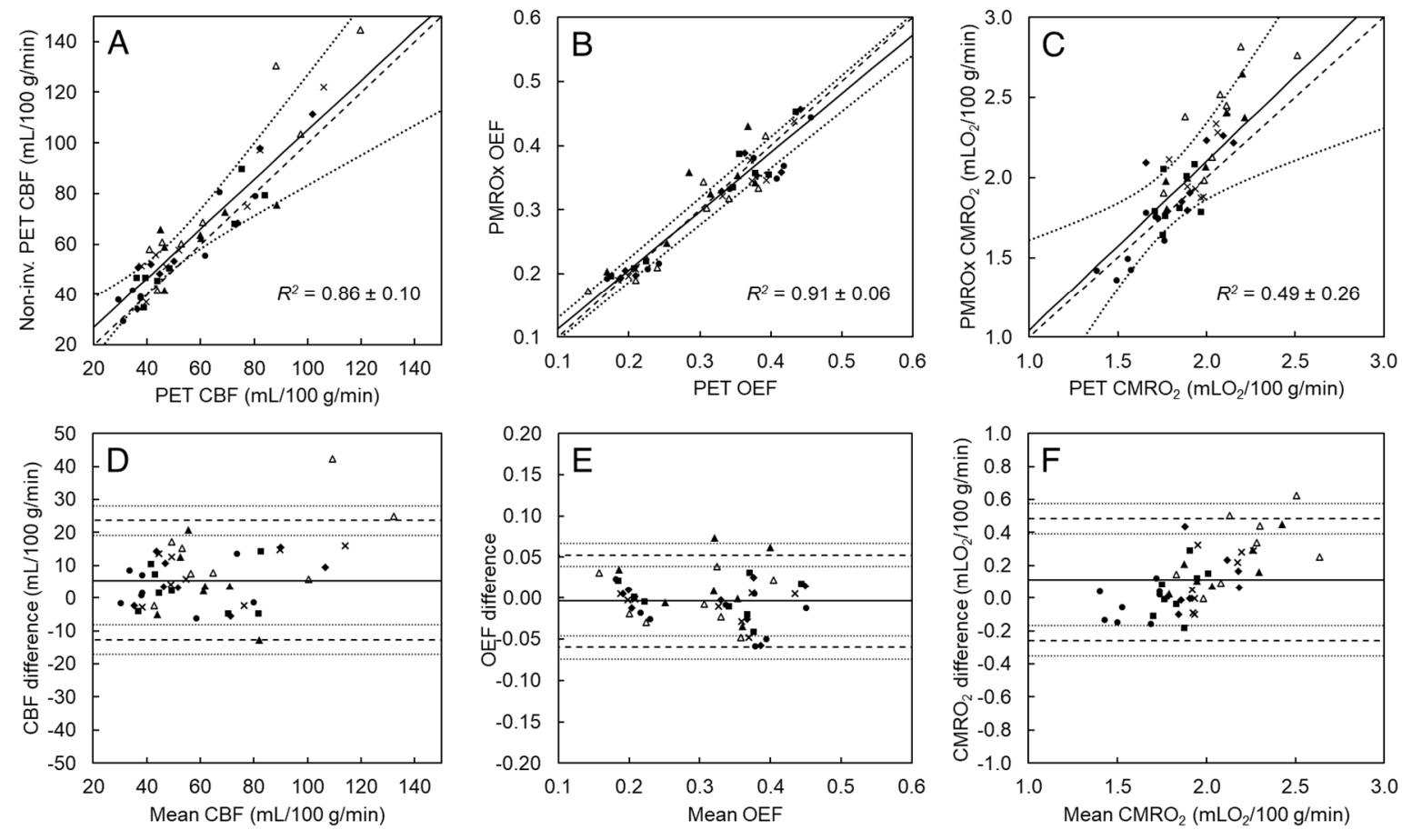

FIGURE 2. (A) Local baseline CBF from noninvasive PET/MR and DBFM. Average regression line is represented by the solid line $(y=0.98 x+7.29 ; 95 \%$ confidence interval $(\mathrm{Cl})$ is represented by the dotted lines). The dashed line is the identity line. Corresponding (B) OEF and (C) $\mathrm{CMRO}_{2}$ results presented average regression line of $y=0.92 x+0.02$ and $y=1.06 x-0.02$, respectively. Bland-Altman plots from the corresponding data are presented in $(D)-(F)$, where the mean is represented by the solid line. The dashed lines represent the limits of agreement ( \pm 2 standard deviations), each with its $95 \% \mathrm{Cl}$ (dotted lines). Mean difference for all VOls was $6.2 \mathrm{~mL} / 100 \mathrm{~g} / \mathrm{min}$ for CBF, -0.004 for OEF and $0.12 \mathrm{mLO} / 100 \mathrm{~g} / \mathrm{min}$ for $\mathrm{CMRO}_{2}$. 


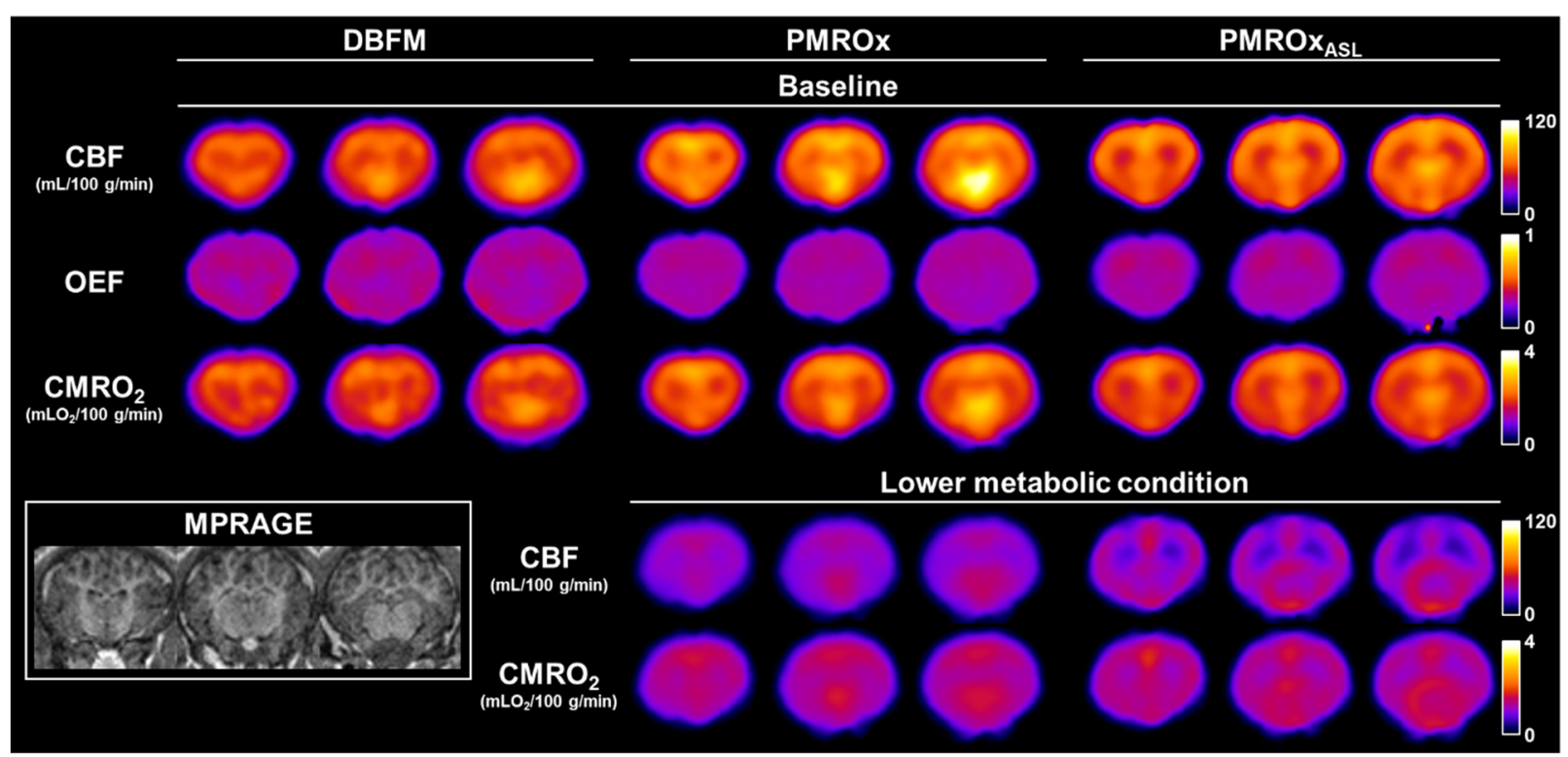

FIGURE 3. Group-wise CBF, OEF and $\mathrm{CMRO}_{2}$ images obtained with DBFM, PMROx and PMROXASL techniques for baseline ( $n=8$, top three rows). CBF and $\mathrm{CMRO}_{2}$ results from PMROx and PMROXASL for the lower metabolic condition $(n=6)$ are presented on the bottom two rows. MPRAGE from one animal was included for anatomical reference. 

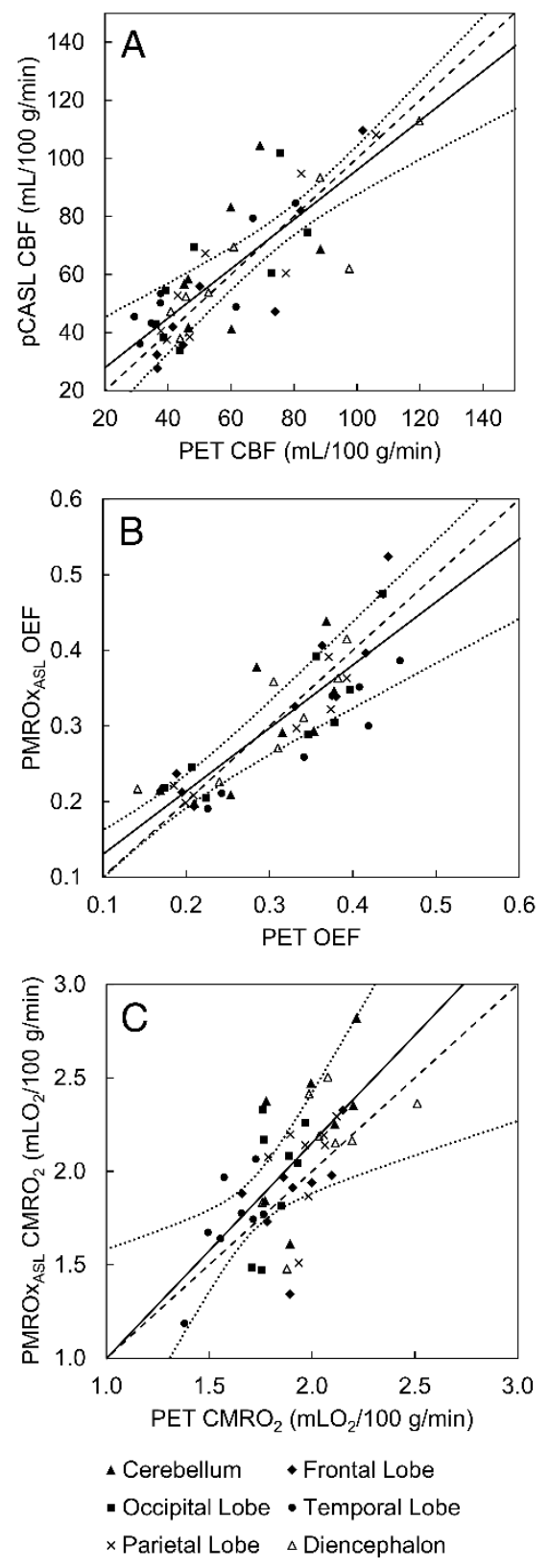

FIGURE 4. (A) Local baseline CBF from pCASL and DBFM. Average regression line is represented by the solid line $(y=0.85 x+10.91 ; 95 \%$ confidence interval is represented by the dotted lines). The dashed line is the identity line. Corresponding (B) OEF and (C) $\mathrm{CMRO}_{2}$ results presented average regression line of $y=0.83 x+0.05$ and $y=1.15 x-0.16$, respectively. 

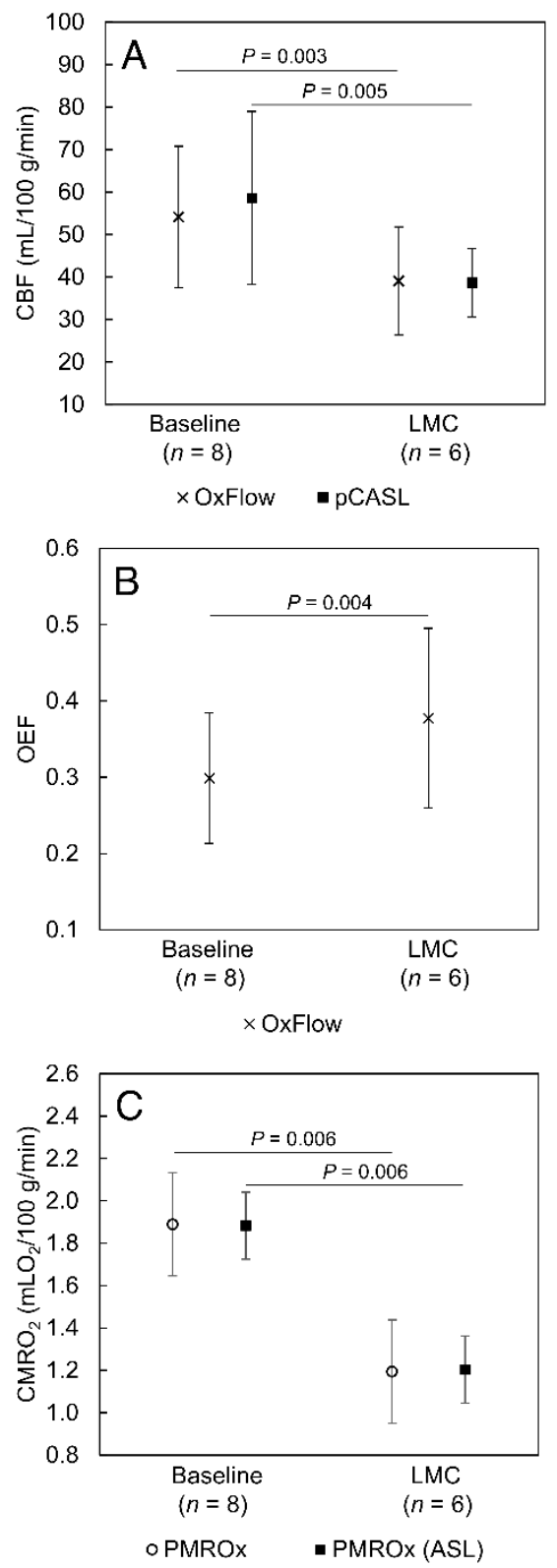

FIGURE 5. (A) WB CBF, (B) OEF and (C) $\mathrm{CMRO}_{2}$ values for baseline and $\mathrm{LMC}$. Significant reductions in WB-CBF and $\mathrm{WB}-\mathrm{CMRO}_{2}$ were observed for both techniques, while a significant increase was observed for WB-OEF. 


\section{TABLES}

TABLE 1. Summary of the regression and correlation analyses performed on the local baseline measurements $(n=8)$ of CBF $(\mathrm{mL} / 100 \mathrm{~g} / \mathrm{min})$, OEF and $\mathrm{CMRO}_{2}\left(\mathrm{mLO}_{2} / 100 \mathrm{~g} / \mathrm{min}\right)$.

\begin{tabular}{ccccc}
\hline & & Slope & Intercept & $\boldsymbol{\rho}$ \\
\hline \multirow{3}{*}{ PMROx } & $\mathrm{CBF}$ & $0.98 \pm 0.20$ & $7.3 \pm 9.8$ & $0.91 \pm 0.10$ \\
& $\mathrm{OEF}$ & $0.92 \pm 0.03^{*}$ & $0.02 \pm 0.01^{\dagger}$ & $0.95 \pm 0.04$ \\
& $\mathrm{CMRO}_{2}$ & $1.06 \pm 0.35$ & $-0.02 \pm 0.63$ & $0.67 \pm 0.20$ \\
\hline \multirow{3}{*}{ PMROx } & $\mathrm{CBF}$ & $0.85 \pm 0.15$ & $10.9 \pm 11.7$ & $0.80 \pm 0.18$ \\
& $\mathrm{OEF}$ & $0.83 \pm 0.13^{*}$ & $0.05 \pm 0.03^{\dagger}$ & $0.87 \pm 0.09$ \\
& $\mathrm{CMRO}_{2}$ & $1.15 \pm 0.41$ & $-0.16 \pm 0.70$ & $0.53 \pm 0.14$ \\
\hline
\end{tabular}

*Significantly different than one.

tSignificantly different than zero. 


\section{GRAPHICAL ABSTRACT}

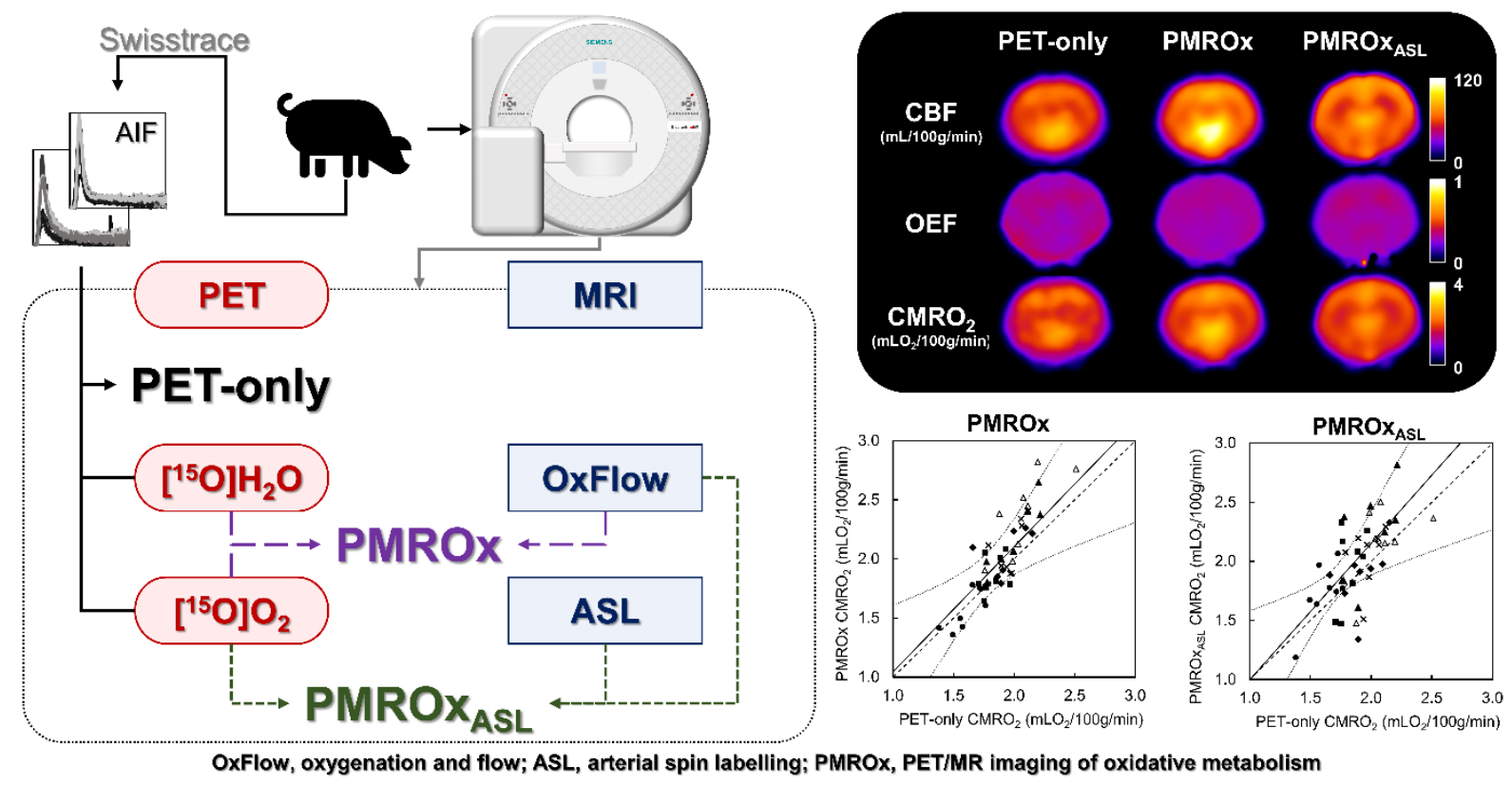




\section{SUPPLEMENTAL DATA}

\section{MR Sequences Acquisition and Analysis Scheme}
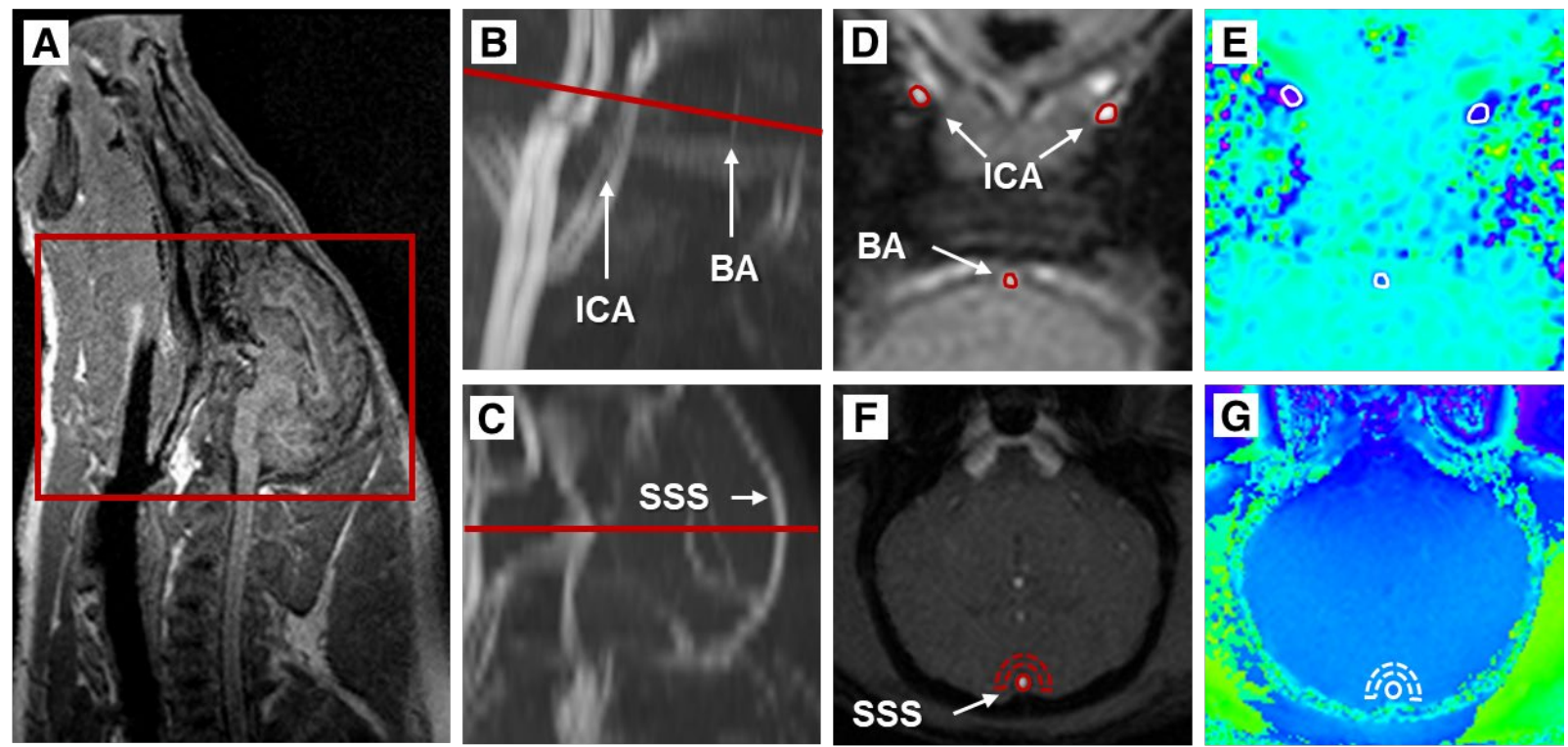

SUPPLEMENTAL FIGURE 1. (A) Sagittal MPRAGE image showing imaging region. MR angiography showing (B) the internal carotid arteries (ICA) and basilar artery (BA), and (C) the superior sagittal sinus (SSS). The red lines represent the slices used to measure WB CBF and $\mathrm{S}_{\mathrm{V}} \mathrm{O}_{2}$. Magnitude and phase images from the slices used to estimate (D)-(E) WB CBF and (F)-(G) $S_{v} O_{2}$. The red regions-of-interest were transferred from the magnitude to the phase image (in white). All images are from one representative animal.

\section{Population-based AIFs}
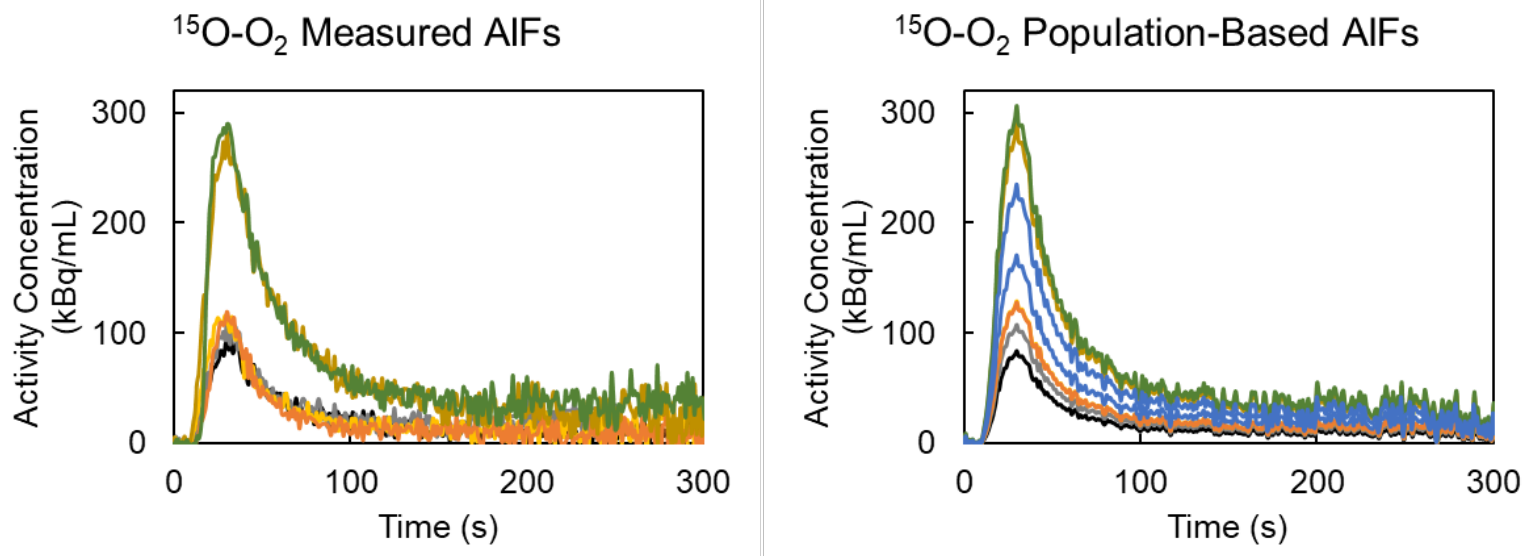

SUPPLEMENTAL FIGURE 2. Measured ${ }^{15} \mathrm{O}_{-} \mathrm{O}_{2}$ AIFs (left) and their respective scaled population-based curves (right). The blue curves represent the population-based AIFs used for the two animals that arterial sampling failed. 


\section{Arterial Blood Measurements}

SUPPLEMENTAL TABLE 1. Summary of arterial blood measurements. No statistical differences were identified in any of the parameters across the acquisitions.

\begin{tabular}{ccc}
\hline & Baseline & LMC \\
\hline Hematocrit (\%) & $25.9 \pm 3.4$ & $25.7 \pm 2.1$ \\
Hemoglobin (g/dL) & $8.3 \pm 1.1$ & $8.3 \pm 0.7$ \\
Partial pressure of oxygen (mmHg) & $230 \pm 100$ & $239 \pm 102$ \\
Partial pressure of carbon dioxide (mmHg) & $40.3 \pm 4.3$ & $41.0 \pm 3.4$ \\
$\mathbf{S}_{\mathrm{a}} \mathbf{O}_{\mathbf{2}}(\%)$ & $99.5 \pm 0.5$ & $99.5 \pm 0.4$ \\
Glucose concentration (mmol/L) & $5.5 \pm 0.8$ & $5.5 \pm 0.4$ \\
\hline
\end{tabular}

\section{Glossary of Variables}

\begin{tabular}{|c|c|c|}
\hline Variable & Description & Unit \\
\hline$A_{o}(t)$ & Oxygen-only component of ${ }^{15} \mathrm{O}-\mathrm{O}_{2}$ arterial input function & $\mathrm{kBq} / \mathrm{g}$ \\
\hline$A_{w}(t)$ & Recirculating water component of ${ }^{15} \mathrm{O}-\mathrm{O}_{2}$ arterial input function & $\mathrm{kBq} / \mathrm{g}$ \\
\hline$C_{a}^{o}(t)$ & ${ }^{15} \mathrm{O}-\mathrm{O}_{2}$ arterial input function & $\mathrm{kBq} / \mathrm{g}$ \\
\hline$C_{a}^{w}(t)$ & ${ }^{15} \mathrm{O}-\mathrm{H}_{2} \mathrm{O}$ arterial input function & $\mathrm{kBq} / \mathrm{g}$ \\
\hline $\mathrm{C}_{a} \mathrm{O}_{2}$ & Arterial content of oxygen & $\mathrm{mLO}_{2} / 100 \mathrm{~mL}$ \\
\hline $\mathrm{CMRO}_{2}$ & Cerebral metabolic rate of oxygen & $\mathrm{mLO}_{2} / 100 \mathrm{~g} / \mathrm{min}$ \\
\hline$E$ & Oxygen extraction fraction & \\
\hline$f$ & Cerebral blood flow & $\mathrm{mL} / 100 \mathrm{~g} / \mathrm{min}$ \\
\hline$H b$ & Hemoglobin concentration & $\mathrm{g} / 100 \mathrm{~mL}$ \\
\hline $\boldsymbol{i}$ & Subscript for local measurements & \\
\hline $\boldsymbol{k}_{2}$ & Efflux rate constant of $\mathrm{H}_{2}{ }^{15} \mathrm{O}$ from blood to brain tissue & $\min ^{-1}$ \\
\hline$p$ & Blood-brain partition coefficient for water & $\mathrm{mL} / 100 \mathrm{~g}$ \\
\hline $\mathrm{P}_{a} \mathrm{O}_{2}$ & Partial pressure of oxygen & $\mathrm{mmHg}$ \\
\hline$S_{a} O_{2}$ & Arterial saturation of oxygen & $\%$ \\
\hline $\mathrm{S}_{v} \mathrm{O}_{2}$ & Venous saturation of oxygen & $\%$ \\
\hline$V_{b}^{w}$ & Cerebral arterial blood volume $\left({ }^{15} \mathrm{O}-\mathrm{H}_{2} \mathrm{O}\right)$ & $\mathrm{mL} / 100 \mathrm{~g}$ \\
\hline$V_{A}^{w}$ & Cerebral arterial blood volume $\left({ }^{15} \mathrm{O}-\mathrm{O}_{2}\right)$ & $\mathrm{mL} / 100 \mathrm{~g}$ \\
\hline$V_{0}^{o}$ & Combination of cerebral arterial and venous blood volumes $\left({ }^{15} \mathrm{O}-\mathrm{O}_{2}\right)$ & $\mathrm{mL} / 100 \mathrm{~g}$ \\
\hline $\boldsymbol{t}$ & Time & $\min$ \\
\hline$T$ & Scan time & $\min$ \\
\hline$w b$ & Subscript for whole-brain measurements & \\
\hline
\end{tabular}

